\title{
Fractional Order Fuzzy Based Virtual Inertia Controller Design for Frequency Stability in Isolated Hybrid Power Systems
}

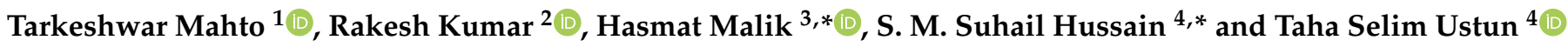 \\ 1 Electrical and Electronics Engineering Department, SRM University AP, Amravati 522502, India; \\ tarkeshwar.m@srmap.edu.in \\ 2 Department of Electrical and Electronics Engineering, M S Ramaiah Institute of Technology, \\ Bengaluru 560054, India; raks4rakesh@msrit.edu \\ 3 Berkeley Education Alliance for Research in Singapore (BEARS), University Town, National University of \\ Singapore (NUS) Campus, Singapore 119077, Singapore \\ 4 Fukushima Renewable Energy Institute, AIST (FREA), National Institute of Advanced Industrial Science and \\ Technology (AIST), Koriyama 963-0298, Japan; selim.ustun@aist.go.jp \\ * Correspondence: elev505@nus.edu.sg (H.M.); suhail.hussain@aist.go.jp (S.M.S.H.)
}

Citation: Mahto, T.; Kumar, R.

Malik, H.; Hussain, S.M.S.; Ustun, T.S. Fractional Order Fuzzy Based Virtual Inertia Controller Design for Frequency Stability in Isolated Hybrid Power Systems. Energies 2021, 14, 1634. https://doi.org/10.3390/ en14061634

Academic Editor: Ali Mehrizi-Sani

Received: 9 February 2021

Accepted: 11 March 2021

Published: 15 March 2021

Publisher's Note: MDPI stays neutral with regard to jurisdictional claims in published maps and institutional affiliations.

Copyright: (c) 2021 by the authors. Licensee MDPI, Basel, Switzerland. This article is an open access article distributed under the terms and conditions of the Creative Commons Attribution (CC BY) license (https:// creativecommons.org/licenses/by/ $4.0 /)$.

\begin{abstract}
In the present era, electrical power system is evolving to an inverter-dominated system from a synchronous machine-based system, with the hybrid power systems (HPS) and renewable energy generators (REGs) increasing penetration. These inverters dominated HPS have no revolving body, therefore, diminishing the overall grid inertia. Such a low system inertia could create issues for HPS with REG (HPSREG) such as system instability and lack of resilience under disturbances. A control strategy, therefore, is required in order to manage this task besides benefitting from the full potential of the REGs. A virtual inertia control for an HPSREG system built with the principle of fractional order (FO) by incorporation of proportional-integral-derivative (PID) controller and fuzzy logic controller (FLC) has been projected. It is utilized by adding virtual inertia into HPSREG system control loop and referred to as FO based fuzzy PID controller for this study. Simulation outcomes states that the advocated FO based fuzzy PID controller has superior control in frequency of the system under frequent load variations. It has been noted that the proposed control scheme exhibits improved efficiency in maintaining specific reference frequency and power tracking as well as disturbance diminution than optimal classic and FO-based controller. It has been validated that, the developed controller effectively delivers preferred frequency and power provision to a low-inertia HPSREG system against high load demand perturbation. In the presented paper, analysis based on sensitivity has also been performed and it has been found that the HPSREG system's is not effected by system parameter and load variations.
\end{abstract}

Keywords: frequency and power; virtual inertia; HPSREG system; fractional order; fuzzy logic controller

\section{Introduction}

Use of renewable energy-based generators (REGs) like solar, wind, geothermal and biomass for power production has grown recently [1]. A microgrid is a collection of REGs, energy storage systems (ESS), and loads that may be recognized as an autonomous network capable of operating in either connected or isolated-grid mode [2,3]. The REGs have based on the power electronic interface and supply power through inverters. This decreases the overall device inertia and causes a microgrid to have less stability than conventional power networks [4]. Such undesirable impact of power electronics together with the intermittent generation profile of REGs might create issues such as extreme fluctuations on power system.

A contemporary method to deal with these drawbacks of inverter-based REG in HPS is to practically mimic the action of synchronous generators into the microgrid, thereby enriching system stability and resilience [5]. Virtual synchronous generators (VSG) resolve this issue 
by imitating the essence of conventional generators electronically and introducing inertia into the power system, stability of the microgrid, output impedance and resiliency [6-10]. A particular aspect of VSG operation is virtual inertia control which tries to emulate prime mover behavior for the improvement in the stability of the system frequency and power [9]. The virtual control of inertia using ESS allows it to act as a traditional generator, showing the system's inertia and damping properties like a true synchronous generator.

Digital inertia regulation may present the ground of upholding the proportion by REGs or distributed generators (DGs) without compromising with stability and durability of the microgrid [11]. In REGs or DGs, instability and cascading outages leading to disruptive incident without virtual inertia control may occur [12]. Digital inertia control has been introduced with various control techniques to resolve frequency and power control issues of microgrid to boost the system frequency stability [11,13-17].

In [11], an virtual inertia control technique was applied on a system using proportionalintegral (PI) control technique based on classical control method. A PI-based virtual inertia control of the wind generator for helping the microgrid in the stability of its frequency was proposed in [13]. The control in deviation of frequency in HPS, a fuzzy based virtual inertia regulation is implemented in [14,15]. In [16], virtual inertia controller designed with model predictive control concept for enhancing the microgrid stability and robustness at the time of higher RES penetration. To improve the stability of an integrated high wind power system a frequency response estimation technique grounded with virtual inertia control was assessed in [17]. To promote frequency regulation in interconnected power systems with HVDC [6], a virtual inertia controller was presented with derivative controlling process.

A suitable trade-off in performance between control and robustness is not easy to achieve in relation to the former control techniques. In addition, the formulation of uncertainty was not considered and built into control methods (i.e., unstructured uncertainty modeling) [6,11,13-17]. Therefore, with the above controlling methods, it is tough to assurance synchronized robust stability and efficiency in an extensive variety of perturbation in demand and generation. Because of the opportunity in formulating uncertainty (i.e., formal modeling of uncertainty) of the system considered [18], method for robust controlling may effectively resolve the issues related to uncertainties. Fractional calculus-based controllers are most effective in controlling the system disturbances. Fractional calculus [19] has found applications in control systems over the last decade and is gaining growing interest from the research community in other fields.

The controllers are needed to suppress the effect produced by the stochastic components of REG, like continuous dissimilarity in frequency of the system. This impacts the quality of the supply power that is needed to be managed within permissible limits in order to avoid malfunctioning of the linked loads. To overcome such situation in power system, a control loop is needed which may generate signals for devices with energy storing capabilities for release (or absorb) extra (or deficit) power from (or to) the grid. In order to satisfy load demands of short-durations, the controller generates signal for the diesel-based generator to deliver more power into the grid. A FO-based fuzzy PID controller [20,21] has been used for this function in the present study and is equated to the performances obtained through FO- and IO- PID controllers.

Considering the above, in current paper proposes a harmonic search (HS) algorithm with a quasi-opposition technique known as a quasi-opposition harmonic search (QOHS) algorithm to optimizing various tunable elements of each considered controller [14,15]. HS algorithm has the ability of identifying the regions with high-performance solution space within a considerable span of time. To boost the solution accuracy and the convergence rate, some improved version of HS have been suggested in [22-25]. By implementing a technique to dynamically tune the key parameters, an enhanced HS algorithm is proposed in [16]. To modal a secondary controller an algorithm is established by integrating the concept of cuckoo optimization algorithm (i.e., egg-laying and immigration mechanisms) into HS algorithm for two real-world models of load frequency control (LFC) problem in [17]. 
In [18], a new technique is projected considering the amalgamation of fuzzy logic controller and HS algorithm to provide the optimal size solution for a hybrid power system considering environmental information's like, demand load, level of solar irradiation and speed of wind). Work in [26] has proposed the controller for deviation of frequency and power by integrating PID and fuzzy controller in the environment of fractional order calculus and tunning the controller parameters tuned with QOHS. Work in [26] has proposed an HS algorithm based on opposition initialization to the problem of power system optimization with specific focus on compensation of reactive power for an isolated HPS model.

Considering form above, in the current paper QOHS algorithm has been advocated to tune the gains of each controller, it is professed for the frequency and power of a HPSREG system outcome not only depends on the optimization technique but also depends on the controller configuration. Therefore, motivated from the above analysis, in this paper, QOHS tunned FO based fuzzy PID controller have been suggested for frequency and power control of HPSREG. Graphical outputs from simulation disclose about the competency of the suggested method of control, which reduces the deviations in frequency competently compared with the classical controller and FO controller. Therefore, provides reliable and quality electric power.

Major contributions of the paper are:

1. The HPSREG model consists of a wind turbine generator (WTG) and diesel engine generator (DEG) along with ESS has been considered to validate the progress in the power demand balance in remote rural and urban areas.

2. ESS unit is designed to mimic inertia along with its basic function of power balancing.

3. The speed governor control mechanism of DEG and WTGs' pitch control action has been explored using capacitive energy storage (CES) along with FO based fuzzy PID controller.

4. A QOHS algorithm has been proposed to optimize various optimizable variables of HPSREG system.

5. The effectiveness of the control system is experienced with uncertain and stochastic variation in load and parameter variation in system.

6. The possible uses of CES in balancing power and, thus, balancing of weak HPSREG system is undertaken.

Rest of paper is as follows; Section 2 gives an elementary introduction about HPSREG system frequency control. Here in, virtual inertia system and the robust FO based fuzzy PID controller for virtual inertia control has been reported in Section 3. In Sections 4 and 5, performance indices for optimization and optimization technique for tunning of optimizable elements of the considered HPSREG model has been discussed, respectively. Simulation results in time-domain are displayed and analyzed in Section 6. Finally, in Section 7, the conclusion is drowned from all the simulation results and analysis on them.

\section{HPSREG System Overview and Modeling}

In the present HPSREG system study, simulated model is independent of convertors and nonlinearities consideration and the system simulation is in a simplified manner by taking linear first order transfer mechanism into account for the components of the HPSREG model. The diesel-based and the wind power generators [27] considered rated capacity is $150 \mathrm{~kW}$ for each with the HPSREG system parameter as defined in Table 1.

The simulation model for the considered HPSREG system has been portrayed in Figure 1. The model is formed by combining DEG, WTG with respective controlling mechanism and virtual inertia controller driven ESS. Total power outputs' incremental change $\left(\triangle P_{T O T A L}\right)$ considered system may be evaluated by (1). 
Table 1. HPSREG system dynamic parameters.

\begin{tabular}{ccc}
\hline Unit & Parameters & \\
\hline & $K_{P 1}=1.25$ & $K_{P 2}=1.0$ \\
& $K_{P 3}=1.4$ & $K_{P C}=0.080$ \\
WTG unit & $K_{I G}=0.9969$ & $K_{T P}=0.0033$ \\
& $T_{P 1}=0.6 \mathrm{~s}$ & $T_{P 2}=0.041 \mathrm{~s}$ \\
& $T_{P 3}=1.0 \mathrm{~s}$ & $T_{W}=4.00 \mathrm{~s}$ \\
\hline & $K_{D}=0.3333$ & $T_{D 1}=1.00 \mathrm{~s}$ \\
DEG unit & $T_{D 2}=2.0 \mathrm{~s}$ & $T_{D 3}=0.025 \mathrm{~s}$ \\
& $T_{D 4}=3.0 \mathrm{~s}$ & \\
\hline ESS unit & $K_{V I}=0.5$ & $\mathrm{~T}_{V I}=10 \mathrm{~s}$ \\
\hline Power system & $H=0.083$ & $\mathrm{D}=0.015$ \\
\hline
\end{tabular}

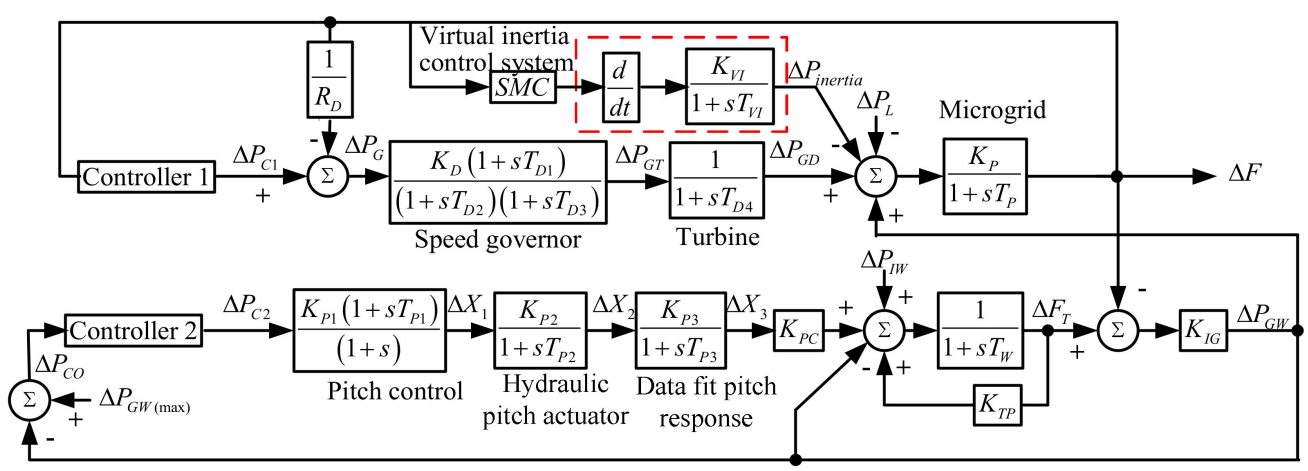

Figure 1. Dynamic model of the HPSREG system.

$$
\Delta P_{T O T A L}=\Delta P_{G D}+\Delta P_{G W}-\Delta P_{\text {inertia }}-\Delta P_{L}
$$

The frequency and power deviation of the HPSREG system considering the effect of controllers, and inertia controls may be obtained as:

$$
\Delta f=\frac{1}{2 H+D}\left(\Delta P_{G D}+\Delta P_{G W}-\Delta P_{\text {inertia }}-\Delta P_{L}\right)
$$

where $\Delta P_{G D}$ is deviation in DEG power output, $\Delta P_{G W}$ is deviation in WTG power output, $\Delta P_{\text {inertia }}$ is deviation in ESS-based inertia power output and $\Delta P_{L}$ is the deviation in load demand.

The machine diagram of the transfer function blocks, presented in Figure 1, comprises the LFC, virtual inertia control alongside the blade pitch controller in DEG, CES and WTG, respectively. A first-order framework explains the dynamics of the WTG, DES and CES. These power electronics based REGs minimize overall device inertia due to the penetration of REGs such as WTG in the HPSREG device and caries undesirable effect to system frequency and voltage stabilization. Virtual inertia control method, together with the LFC or when the LFCs are not adequate, is highly anticipated to equalize for unbalance of active power in the HPSREG method. A first-order derivative transfer mechanism with gain $\left(K_{V I}\right)$ and time delay $\left(T_{V I}\right)$ has been used in virtual inertia control block [28]. The parameters of HPSREG system are presented in Table 1.

\subsection{Inertia Response for Frequency}

The main mechanisms, the inertia response, LFC and the primary control process, define frequency control in the present work. The controllers have not yet been triggered during the inertia response phase, so the kinetic energy from the generators balance out the power requirement when a frequency deviation occurs. After any unbalance, the primary 
controller suppresses the deviation in frequency as per new power balance condition. If the primary control system is not able to minimis the deviation in frequency and power, the secondary controllers, like inertia control and LFC, restores the system frequency after the disturbance within its specified range [14].

The inertia response of power system is characterized by its kinetic energy under conventional consideration. Total systems' kinetic energy ( $\left.E_{K E}\right)$ (i.e., spinning mass), considering its rotational loads, may be formulated as $[18,29]$.

$$
E_{K E}=\frac{1}{2} J \omega^{2}
$$

where, $J$ is systems' moment of inertia $\left(\mathrm{kg} / \mathrm{m}^{2}\right)$ and is $\omega$ the systems' angular frequency $(\mathrm{rad} / \mathrm{s})$. As per torque balance equation, depending on the spinning mass of system the rate of change of rotor speed varies and may be expressed as follows:

$$
T_{m}-T_{e}=\frac{P_{m}}{\omega}-\frac{P_{e}}{\omega}=J \frac{d \omega}{d t}
$$

where, $T_{e}$ is the electrical torque, $T_{m}$ is the mechanical torque, $P_{m}$ is the mechanical power and $P_{e}$ is the electrical power, of the system [29].

The $E_{K E}$ stored in a system is proportionate of its rated power and is termed as inertia constant of system $(H)[18]$.

$$
H=\frac{E_{K E}}{S}
$$

where, $S$ denotes system rated apparent power in $(V A)$.

In general, rate of change of frequency (ROCOF) of system is undertaken to control the deviation in power and frequency under the varying load demand environment. In power system ROCOF is considered for evaluate its inertia. Therefore, $H$ is calculated with ROCOF as follow $[18,29]$.

$$
\frac{d \omega}{d t}=\frac{\omega\left(P_{m}-P_{e}\right)}{2 H s}
$$

\subsection{WTG Modeling}

The WTG power output varies as a cubic function of wind velocity $\left(V_{w}\right)$, characteristics has been demonstrated in [30]. The wind turbine's mechanical output power is articulated by (7)

$$
P_{W}=\frac{1}{2} \rho A_{r} C_{p} V_{w}^{3}
$$

where $\rho$ is air density $\left(\mathrm{kg} / \mathrm{m}^{3}\right), A_{r}$ is swept area of blade $\left(\mathrm{m}^{2}\right)$ and $C_{p}$ is power co-efficient which is a function of tip speed ratio and blade pitch angle. Various elements of the WTG system may be articulated by means of transfer function depiction by (8)-(13).

$$
\begin{gathered}
\Delta F=\left(\frac{K_{P}}{1+s T_{P}}\right)\left[\Delta P_{G W}+\Delta P_{G D}-\Delta P_{\text {inertia }}-\Delta P_{L}\right] \\
\Delta P_{G W}=K_{I G}\left[\Delta F_{T}-\Delta F\right] \\
\Delta F_{T}=\left(\frac{1}{1+s T_{W}}\right)\left[K_{T P} \Delta F_{T}-\Delta P_{G W}+K_{P C} \Delta X_{3}+\Delta P_{I W}\right] \\
\Delta X_{3}=\Delta X_{2}\left[\frac{K_{P 3}}{1+s T_{P 3}}\right] \\
\Delta X_{2}=\Delta X_{1}\left[\frac{K_{P 2}}{1+s T_{P 2}}\right]
\end{gathered}
$$




$$
\Delta X_{1}=\Delta P_{C W}\left[\frac{K_{P 1}\left(1+s T_{P 1}\right)}{1+s}\right]
$$

\subsection{DEG Modeling}

In HPSREG system, the deficit power is autonomously supplied by DEG to balance the load demand conditional on the load demand and WTG along side virtual inertia control based CES. The operating time of the DEG should be reduced, since its lifecycle is inversely proportionate to its supplied energy. Various elements of DEG are specified by means of first-order transfer functions as itemized in (14)-(16).

$$
\begin{gathered}
\Delta P_{G D}=\left(\frac{1}{1+s T_{D 4}}\right) \Delta P_{G T} \\
\Delta P_{G T}=\left(\frac{K_{D}\left(1+s T_{D 1}\right)}{\left(1+s T_{D 2}\right)\left(1+s T_{D 3}\right)}\right) \Delta P_{G} \\
\Delta P_{G}=\Delta P_{C D}-\frac{\Delta f}{R_{D}}
\end{gathered}
$$

\subsection{Virtual Inertial Control for HPSREG System}

Virtual inertia control is definite an operational particle of a VSG, in this the behavior of a system inertia is mimicked for improving LFC [7-10]. The key principle of virtual inertia controller is the derivative control determined by the ROCOF for an additional active force during the contingencies for the pre-defined values of HPSREG system. Derivative control in frequency calculation is hypersensitive to the tone. To overcome such problems a low-pass filter is introduced into the control. In the filter modeling ESSs' dynamics are also taken care (i.e., quick action) behavior. Therefore, if REGs in the HPSREG system had inertia comparable to conventional power units, like synchronous machines, then the virtual inertia controller will contribute to the HPSREG systems. Thus, the virtual inertia controller mimics the characteristics of synchronous generator, adding to the overall inertia of the HPSREG system and boosting the frequency stability of the system. It has been assumed in this study that the power of inertia is emulated through the mounted ESS. In case of any deviation in frequency, the deficit power is supplied by the virtual inertia controller based CES system, and may be expressed as follow [6,16,31]

$$
\Delta P_{\text {intertia }}=\frac{K_{V I}}{1+s T_{V I}}\left[\frac{d(\Delta f)}{d t}\right]
$$

where $K_{V I}$ is the gain of virtual inertia controller, $T_{V I}$ is the time constant of virtual inertia controller for the ESS control and $\Delta f$ is the system frequency deviation.

\section{System Controller Design}

In this article, the most important goals of the employed controllers are:

- to capture from the REGs the full power,

- to regulate the frequency and power deviation, and

- to control of energy in the HPSREG between generation and consumption.

This section provides a thorough overview regarding design and execution for the standard fuzzy PID controllers based on PID and FO.

\subsection{FO Calculus Basic}

Fractional calculus is an extension of the nth order that successively differs from the integral of an arbitrary function that has the order as any real value. The combined operator denoted as fractional operator (i.e., $a D_{b}^{\alpha}$ ) is expressed in fractional calculus (where $a$ is the operators' upper limit, $b$ is the operators' lower limits and $\alpha \in R$ is the order of fractional 
operator). The operator in the single expression defines both, fractional differential and the fractional integral in (18) [32,33].

$$
{ }_{a} D_{b}^{\alpha}=\left\{\begin{array}{cl}
\frac{d^{\alpha}}{d t^{\alpha}} & R(\alpha)>0, \\
1 & R(\alpha)=0, \\
\int_{a}^{b}(d t)^{-\alpha} & R(\alpha)<0,
\end{array}\right.
$$

Fractional calculus has three main definitions viz. definition from Grunwald-Letnikov, definition from Riemann-Liouville and definition from Caputo [34]. Out of these, RiemannLiouville's definition of fractional operator is the very popular and in use [32-35] and is quantified as in (19)

$$
{ }_{a} D_{b}^{\alpha} f(t)=\frac{1}{G(m-a)} \frac{d^{m}}{d t^{m}} \int_{a}^{b} \frac{f(\tau)}{(t-\tau)^{\alpha+1-m}} d \tau
$$

where $m$ is the integer part of $\alpha, m-1<\alpha<m, m \in N, f(t)$ is the applied function and $\Gamma(x)$ is the Euler's gamma function of $x$.

\subsection{Conventional and FO Based PID Controllers}

The transfer function of classical PID controller $\left(G_{C}(s)\right)$ is having the nature, as in [36].

$$
G_{C}(s)=\frac{U(s)}{E(s)}=K_{p}+\frac{K_{i}}{s^{\lambda}}+K_{d} s^{\mu}
$$

where, $G_{c}(s)$ represents' controller transfer function, $E(s)$ represents' controller error signal and $U(s)$ represents' controller output signal; $K_{p}, K_{i}$ and $K_{d}$ are the PID controllers' proportional, integral and derivative gains respectively; $\mu$ and $\lambda$ represents the differential and integral operator of the controller. Different values of $\mu$ and $\lambda$ determine the nature of classical controllers, like $\mu$ and $\lambda$ as $(\{1,1\}$ or $\{1,0\}$ or $\{0,1\}$ or $\{0,0\})$ resembles to the conventional -PID, PD, PI and P controllers, respectively.

Introduction of fractional nature to the conventional control system considering noninteger order choice for differential and integral operator. Therefore, differential and integral operator introduces two extra independent optimizable variables in the FO controller then its IO counterpart. Thus, few conceivable FO control system may have nomenclature like $P I^{\lambda} D^{\mu}, P I^{\lambda}, P D^{\mu}, P I D^{\mu}$ controllers and so on.

The schematic presentation for conventional PID and FO-PID control system in the $\lambda-\mu$ plane defines the order of the fractional operator. The differential and integral operators' order may vary along horizontal and vertical axis [37].

\subsection{FO Based Fuzzy PID Control System}

If the order for FLC inputs (i.e., rate of change in error) and output (i.e., the integral) are integer values (i.e., $\mu=1$ and $\lambda=1$ in Figure 2), then it is considered as traditional fuzzy PID control system. However, if order for FLC inputs and output in a fuzzy PID controller is based on FO then such control system are called as FO fuzzy PID control system. In the literature it has been demonstrated that, optimizing the MFs shape in a fuzzy controller having less influence in efficiency front for a closed loop system incomprehension to scaling factor (SF) based FLC [38]. 


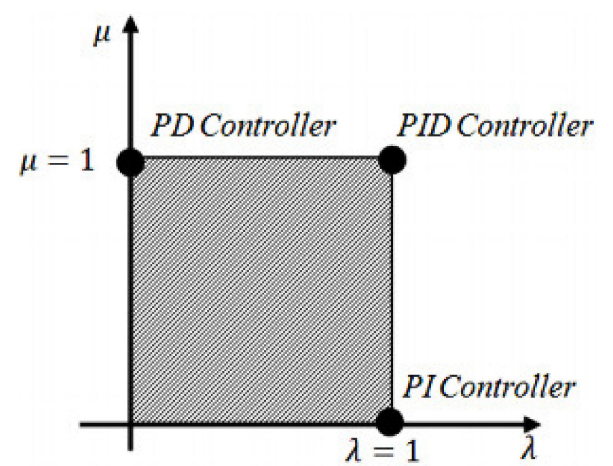

Figure 2. Interpretation for FO-PID and IO-PID control system.

In the present analysis, therefore, the emphasis is given to the conventional MFs and rule base for the FLCs in IO- as well as FO- based fuzzy PID controllers [39]. Optimizing the $\mathrm{SF}$ variables (i.e., $K_{a}, K_{b}, K_{P I}$ and $K_{P D}$ ) along side the $\mathrm{FO}$ variables (i.e., $\mu$ and $\lambda$ ) in IOas well as FO- based fuzzy PID controllers to attain optimum performance in time domain is carried out.

The FLC consists of four main processes, (a) fuzzification of input signal, (b) rule base designing, (c) inference mechanism (i.e., aggregation) and (d) defuzzification of FLC output signal. In fuzzification process the input crisp value is transformed to a fuzzy value with the assistance of knowledge based information. In literature, there are numerous curve patterns available for fuzzification of the crisp input values, like trapezoidal, Gaussian and triangular. In this work, triangular MFs are used in the fuzzification process. Fuzzification is followed by aggregation, it is the method of generating single fuzzy set representation for collective outputs of each rule from the rule-base. It is carried out only once for each variable at output, just before the step of final defuzzification process. As long as the process of aggregation is commutative, then the order of rule-base execution is not of any importance. In present work, a single fuzzy set represents all the rules output and its MF allocates a weight to each output value. Aggregation process is followed by defuzzification process. In the defuzzification process, the output received is a single crisp number and the input for it is the fuzzy output of aggregation. Though, the final output of FLC controller is a single crisp number, fuzziness of the controller assists in the intermediate stage rule-base. However, the output after aggregation step is always consists of a range of values in a form of a fuzzy set and therefore defuzzification is a must process in order to obtain a single crisp number. There are five built-in defuzzification methods supported: middle of maximum (the average of the maximum value of the output set), centroid, bisector, smallest of maximum and largest of maximum. In the carried work centroid method of defuzzification is used, which yields the centre of the area under the aggregate fuzzy set $[40,41]$.

In a FLC most often general forms of the MFs and rule base are considered.

mboxfigfig:energies-1123924-f003 and Table 2 represents the general forms (i.e., fixed shape) for MFs and rule base of FLC, respectively. The MFs as depicted in Figure 3 are considered to be of general forms only to reduce the computational cost of the algorithm. In similar fashion the rule based has also been considered in its general forms as optimization the rule based is a complex process and also the cost of computation increases. The fuzzy linguistic variables LN, SN, ZE, SP and LP represent Large Negative, Small Negative, Zero, Small Positive and Large Positive, respectively. The considered model diagram for the proposed FO based fuzzy PID controller is depicted in Figure 4. 


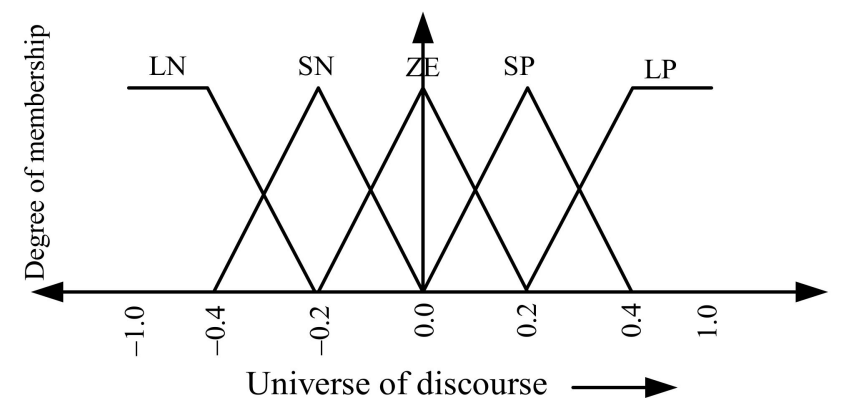

Figure 3. MFs for error, fractional derivative of error and FLC output.

Table 2. Rule base for error, fractional rate of error and FLC output.

\begin{tabular}{cccccc}
\hline$\frac{d^{\mu} \boldsymbol{e}}{d t}$ & LN & SN & ZE & SP & LP \\
\hline LP & ZE & SP & LP & LP & LP \\
SP & SN & ZE & SP & LP & LP \\
ZE & LN & SN & ZE & SP & ZP \\
SN & LN & LN & SN & SP \\
LN & LN & LN & LN & SE \\
\hline
\end{tabular}

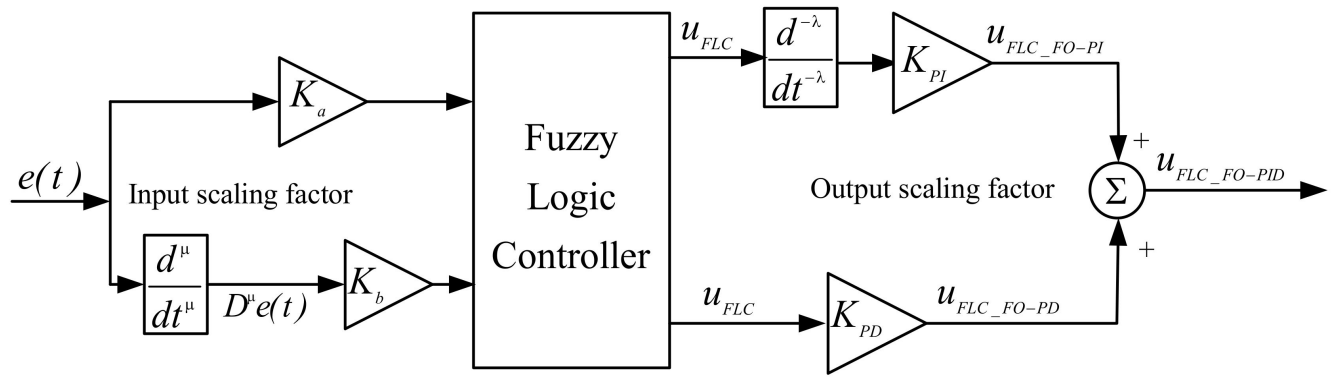

Figure 4. Representation of FO based fuzzy PID controller.

\section{Performance Index}

For the output activity control from the controllers of Figure 1, the tunable parameters need to be optimally tunned. For this, time integral output indices, such as (a) absolute error integral (IAE), (b) squared error integral (ISE), (c) time multiplied absolute error integral (ITAE) and (d) time multiplied squared error integral (ITSE), are quite helpful. Expressions are indicated in (21)-(24) for these four-time domain output indices.

$$
\begin{aligned}
\text { IAE } & =\int_{0}^{\infty}|\Delta f| d t \\
\text { ISE } & =\int_{0}^{\infty}|\Delta f|^{2} d t \\
\text { ITAE } & =\int_{0}^{\infty} t|\Delta f| d t \\
\text { ITSE } & =\int_{0}^{\infty} t|\Delta f|^{2} d t
\end{aligned}
$$


where $\triangle F$ is frequency deviation and $t$ is sampling time consideration. The calculation of IAE, ITAE, and ITSE are generated by the program at the end and are equated for demonstrating the success of each considered controllers [42]. The controllers used in the present study for the same cause are tuned considering ISE as an objective function, subjected to the limits for all tunable variables. therefore, the optimization problem may be articulated as a constrained one, as mentioned in (25)-(29).

$$
\text { Minimize J (=ISE) }
$$

Subjected to:

(a) For classical controllers:

$$
\left.\begin{array}{l}
K_{P j}^{\min } \leq K_{P j} \leq K_{P j}^{\max } \\
K_{I j}^{m i n} \leq K_{I j} \leq K_{I j}^{\max } \\
K_{D j}^{\min } \leq K_{D j} \leq K_{D j}^{\max }
\end{array}\right\}
$$

(b) For CES unit:

$$
\left.\begin{array}{rl}
K_{V I}^{\min } & \leq K_{V I} \leq K_{V I}^{\max } \\
T_{V I}^{\min } \leq T_{V I} \leq T_{V I}^{\max }
\end{array}\right\}
$$

(c) For SFs of FLC:

(i) Input

$$
\left.\begin{array}{l}
K_{a}^{\min } \leq K_{a} \leq K_{a}^{\max } \\
K_{b}^{\min } \leq K_{b} \leq K_{b}^{\max }
\end{array}\right\} a \text { and } b=1 \text { or } 2
$$

(ii) Output

$$
\left.\begin{array}{rl}
K_{P I j}^{\min } & \leq K_{P I j} \leq K_{P I j}^{\max } \\
K_{P D j}^{\min } & \leq K_{P D j} \leq K_{P D j}^{\max }
\end{array}\right\}
$$

where $K_{V I}, T_{V I}$ are the virtual inertial controller variables; $K_{a}, K_{b}$ are the input $\mathrm{SF}$ of the FLC and $K_{P I j}, K_{P D j}$ are the output SF of FLC. In (26)-(29), min and max are the minimum and maximum values of the respective variables, whereas $j=1,2$ as per controller 1 or 2 .

\section{Optimization Algorithm}

\subsection{Fundamentals of HS Algorithm}

A new alternative in the field of meta-heuristic algorithm with derivative-free feature simulating natural as well as systematic process has been introduced in 2001 by Geem et al. [43] and is termed as HS. It gains inspiration through studying the process of building better state of harmony by the musicians via exploring diverse permutation and combination of harmony. In HS optimization process, there exists an analogous relation between the musicians' creating musical harmony and the optimized solution vector. Similarly, there lies an analogy between the musicians' process their instruments pitches for improvement in harmony and optimization search patterns. The main characteristics of HS algorithm are like, [44,45]

(a) fewer mathematical calculations are needed,

(b) stochastic random searches are involved and

(c) generating better solution vector after investigative all the existing solution vectors.

Three main steps are used to describe the process of optimization for HS algorithm, as explained beneath,

(a) Initialization: involves defining of algorithm parameters and objective function; and initialization of harmony memory (HM).

(b) Harmony improvisation: involves randomization and the process of pitch adjustment for creating new solution vector and comparing it with HM stored solution vector.

(c) Selection: involves selection and storing the best solution vector in HM until the termination criteria is encountered. 
Algorithm 1 presents the pseudo code of HS algorithm and the symbols practiced are explained in $[36,37]$.

\section{Algorithm 1. HS Algorithm}

1. Set the parameters: $H M S, H M C R, P A R, B W, N I$ and $d$.

2. Initialize the HM and calculate the objective function value for each harmony vector.

3. Improvise the HM filled with new harmony $X^{\text {new }}$ vectors as follows:

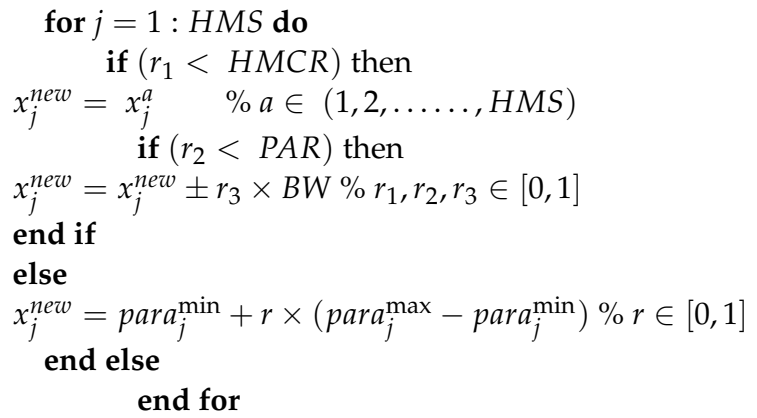

4. $\quad$ Update the HM as $X^{\text {worst }}=X^{\text {new }}$ if $f\left(X^{\text {new }}\right)<f\left(X^{\text {worst }}\right)$.

5. If NI is completed, return the best harmony vector $X^{\text {best }}$ in the HM; otherwise go back to Step 3.

\subsection{Quasi-Opposition Learning: A Concept}

In the field of intelligent computation practice opposition-based learning (OBL) is marked to improve the rate of convergence [46]. From the literature it has been discovered that the probability of reaching to global optimum solution vector is high with oppositional solution vector in comparison to any random solution vector [47]. However, Rahnamayan et al. in [48] have established that the quasi-opposite solution vector have more probability for closer attainment to the global solution than the opposite solution vector. Therefore, the opposite and quasi-opposite numbers, opposite and quasi-opposite points, as employed in OBL and quasi-opposition concept, are described in [49-51].

\subsection{Quasi-Oppositional Population Initialization}

In QOHS Algorithm, similar to other population-based algorithms, first solution vector (i.e., optimization population) is randomly initialized. After utilizing the concept of quasi-oppositional learning concept on the random initialized population a fitter solutions vector may be accomplished without having any prior knowledge about the solution vector(s). The step by process of quasi-oppositional population initialization has proposed in [50], as follows

(a) Random population initialization with uniformly distributed,

(b) Formation of population using quasi-opposite concept,

(c) Evaluation of objective function for all the individuals and

(d) Selection of fittest population set from the initial population set.

\subsection{Quasi-Oppositional Generation Jumping}

The optimization process practiced with the present solution vector may lead to jumping to a new optimized better solution vector then the present one [50]. Generation of new populations after randomization and pitch adjustment process, the formation of population based on quasi-opposite concept and jumping probability (called as, jumping 
rate $\left.\left(J_{r}\right)\right)$, HM size fittest individuals are nominated from the combined population [50]. For approximating the quasi-opposite population for generation jumping, the opposite of each variable and its middle point is calculated dynamically as described in [50]. Hence, as the search process advances, the search space range for new points goes on reducing with respect to its the initial range [50].

\subsection{QOHS Algorithm}

Considering the above sub-sections discussions, the Algorithm 2 presents the pseudocode for QOHS algorithm [50]. Step 2 and 3 of Algorithm 2 articulates the random HM initialization and quasi-oppositional HM initialization, respectively, while Step 6 pronounces the engagement of the quasi-oppositional generation jumping in the QOHS algorithm $[50,51]$.

\section{Algorithm 2. QOHS Algorithm}

1. Set the parameters: $H M S, H M C R, P A R^{\min }, P A R^{\max }, B W^{\min }, B W^{\max }$, and $N I$.

2. Initialize the $\mathrm{HM}$ with $X_{0_{i, j}}$.

\section{3. \% Quasi-oppositional HM initialization}

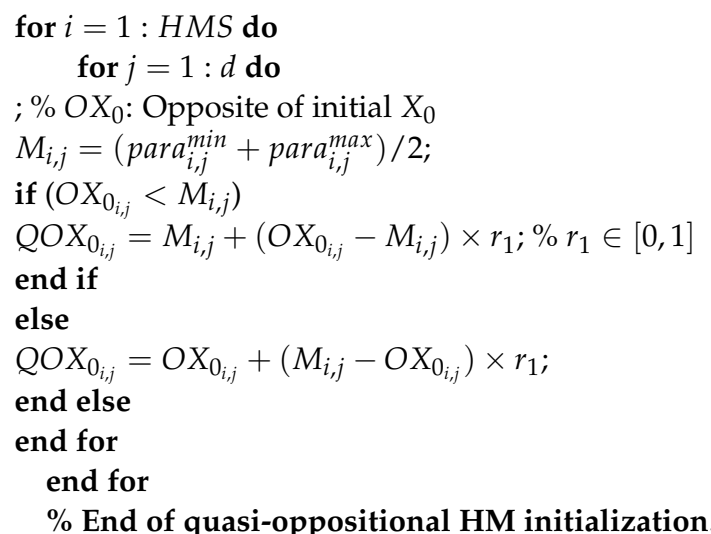

$\%$ End of quasi-oppositional HM initialization.

Select HMS fittest individuals from set of $\left\{X_{0 i, j}, Q O X_{0 i, j}\right\}$ as initial HM; HM being the matrix of fittest Xvectors

4. Improvise a new harmony $X^{\text {new }}$ as follows:

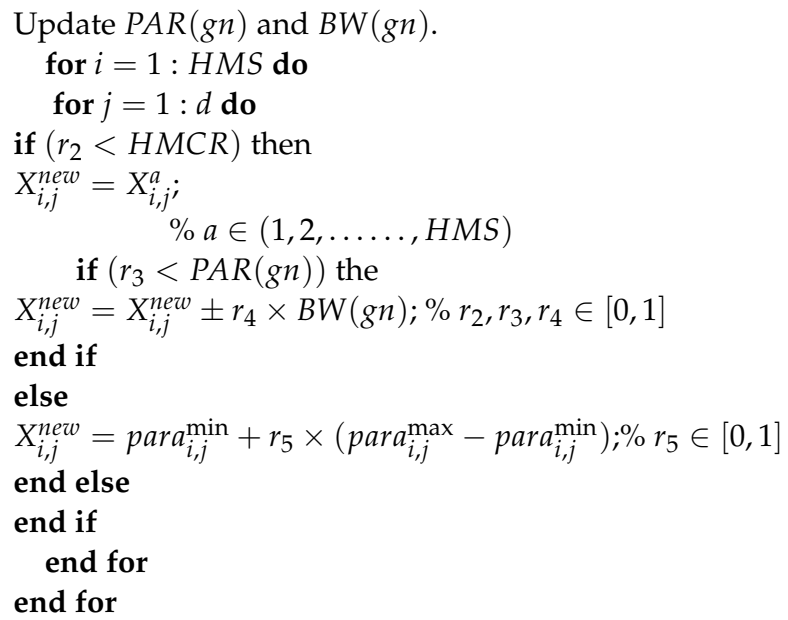

5. Update the HM as $X^{\text {worst }}=X^{\text {new }}$ if $f\left(X^{\text {new }}\right)<f\left(X^{\text {worst }}\right)$ 


\section{Quasi-opposition based generation jumping}

if $\left(r_{6}<J_{r}\right) \% r_{6} \in[0,1], J_{r}$ : Jumping rate

$$
\text { for } i=1: H M S \text { do }
$$

for $j=1: d$ do

$O X_{i, j}=\operatorname{para}_{i, j}^{\min }(g n)+\operatorname{para}_{i, j}^{\max }(g n)-X_{i, j}$;

$\% \operatorname{para}_{i, j}^{\min }(g n)$ : minimum value of the $j$ th variable of the $i$ th parameter in the current generation $(g n)$

$\% \operatorname{para}_{i, j}^{\max }(g n)$ : maximum value of the $j$ th variable of the $i$ th parameter in the current generation $(g n)$

$M_{i, j}=\left\{\operatorname{para}_{i, j}^{\min }(g n)+\operatorname{para}_{i, j}^{\max }(g n)\right\} / 2$;

if $\left(X_{i, j}<M_{i, j}\right)$

$\mathrm{QOX}_{0_{i, j}}=M_{i, j}+\left(O X_{0_{i, j}}-M_{i, j}\right) \times r_{7} ; \% r_{7} \in[0,1]$

end if

else

$\mathrm{QOX}_{0_{i, j}}=O X_{0_{i, j}}+\left(M_{i, j}-O X_{0_{i, j}}\right) \times r_{7}$;

end else

end for

end for

end if

Select HMS fittest HM from the set of $\left\{X_{i, j}, Q O X_{i, j}\right\}$ as current HM.

$\%$ End of quasi-oppositional generation jumping.

7. If NI is completed, return the best harmony vector $X^{\text {best }}$ in the HM; otherwise go back to Step 4 .

\section{Result Demonstration and Analysis}

The results obtained from simulation of the HPSREG system using MATLAB/Simulink in order to verify and assess the proposed controller for virtual inertia control based on FO based fuzzy PID controller (i.e., named as "PID-With-VI-FO-F-PID" for simulation purpose). The functioning of "PID-With-VI-FO-F-PID" simulation model has been compared with FO based PID for virtual inertia control (i.e., named as "PID-With-VI-FO-PID" for simulation), PID based virtual inertia control (i.e., named as "PID-With-VI-PID" for simulation) and excluding virtual inertia control (i.e., named as "PID-without-VI") based HPSREG system considering the REGs nature variety and, load demand alteration to validate its capability of frequency and power control. The PID controllers of the DEG, the WTG along with the FO based PID and PID controller gain for virtual inertia control are all tuned using the QOHS algorithm. Hence, the analysis of frequency and power stability has been investigated for diverse operating conditions through the following scenarios, considering Table 1 for system simulation parameters.

\subsection{Case Study-A: Step Load Perturbation}

In first scenario, the studied HPSREG system working alongside the considered virtual inertia control-based on FO based fuzzy PID controller is investigated and estimated by employing load patterns of a $10 \%$ step load perturbation (SLP) at time $t=1 \mathrm{~s}$ as revealed in Figure 5.

The display of Figure 6 presents the deviation of frequency and power for the studied HPSREG system considering different strategies of control that are named as "PIDWith-VI-FO-F-PID", "PID-With-VI-FO-PID" "PID-With-VI-PID" and "PID-without-VI" for simulation purpose under the impact of a $10 \%$ SLP. 


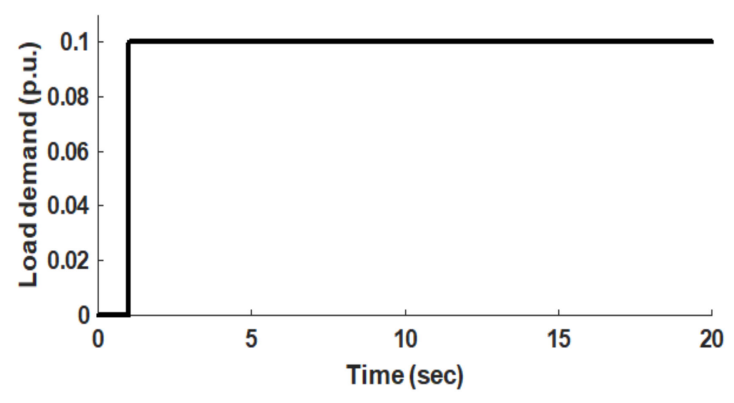

(a)

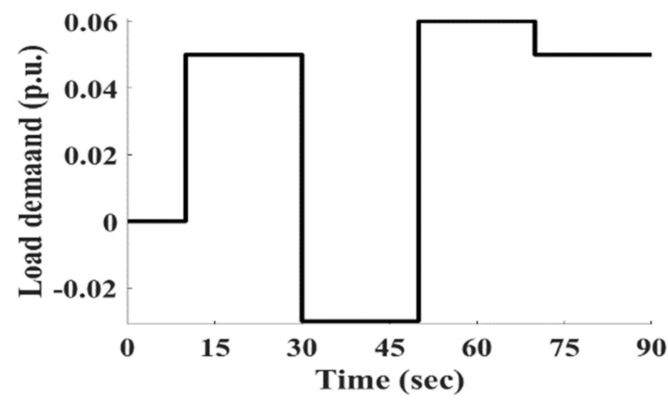

(b)

Figure 5. Load demand pattern (a) 10\% step increase in load demand and (b) Random load demand.

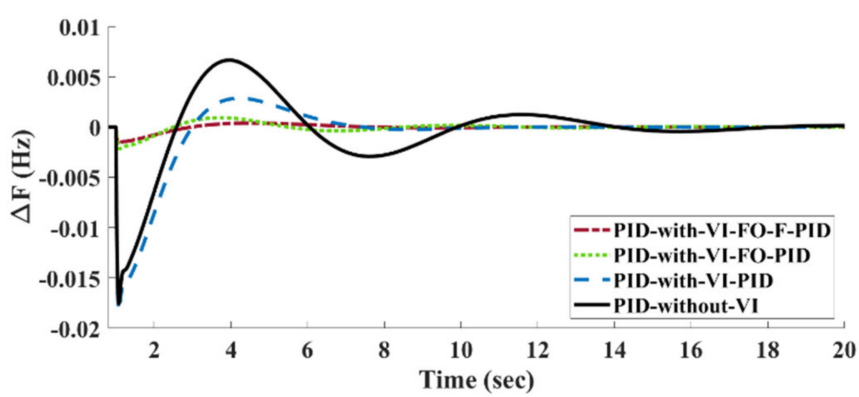

(a)

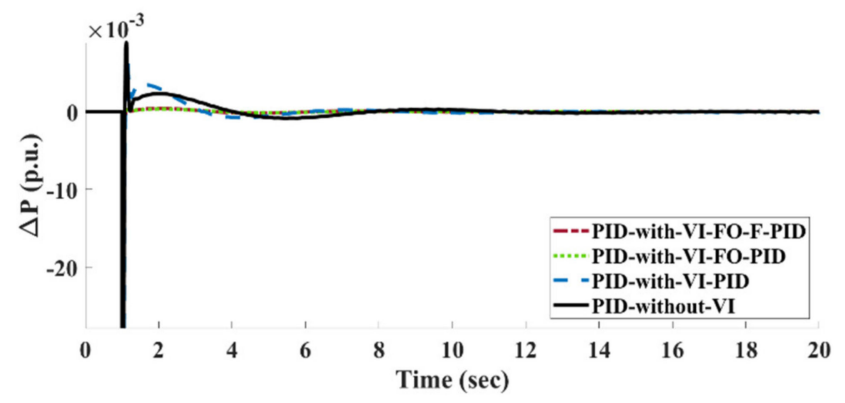

(b)

Figure 6. Dynamic response of HPSREG for $10 \%$ step increase in load demand (a) $\triangle F(H z)$ and (b) $\Delta P($ p.u. $)$.

It is noted from Figure 6, the presented virtual inertia control-based on FO based fuzzy PID controller delivers exceptional operation with superior decrease in frequency and power excursions in parallel to other strategies of control. Where the frequency deviation of the HPSREG system without virtual inertia controller has been maintained within $\pm 0.0176 \mathrm{~Hz}$, in the cases of $10 \%$ SLP. While the studied HPSREG system with the virtual inertia controller based on PID gives a frequency change of $\pm 0.0126 \mathrm{~Hz}$ during the connection of a $10 \%$ SLP at $t=1 \mathrm{~s}$. On the other hand, the deviation of frequency for the HPSREG system considering virtual inertia controller-based on FO based PID has upheld a $\pm 0.0022 \mathrm{~Hz}$ frequency deviation in this case, whereas, with virtual inertia controller-based on FO based fuzzy PID control process may uphold the deviation of frequency within a $\pm 0.0017 \mathrm{~Hz}$. The numerical estimates of dynamic response profile in terms of rise time $\left(T_{r}\right)$, settling time $\left(T_{S}\right)$, maximum overshoot $\left(M_{P}\right)$ and peak time $\left(T_{P}\right)$ as presented in Table 3 showing the superior performance of the FO-F-PID controller compared to FO-PID and PID controllers in virtual inertia control for step load disturbance in HPSREG system. 
Table 3. Comparative study of dynamic responses offered by the HPSREG under step load perturbation.

\begin{tabular}{|c|c|c|c|c|c|c|c|c|}
\hline Controller & $\begin{array}{l}T_{r} \\
\text { (s) }\end{array}$ & $T_{s}(\mathrm{~s})$ & $M_{P}$ & $T_{P}(\mathrm{~s})$ & $\begin{array}{c}\text { ISE } \\
\left(\times 10^{-5}\right)\end{array}$ & $\begin{array}{c}\text { ITSE } \\
\left(\times 10^{-5}\right)\end{array}$ & $\begin{array}{c}\text { IAE } \\
\left(\times 10^{-5}\right)\end{array}$ & $\begin{array}{c}\text { ITAS } \\
\left(\times 10^{-5}\right)\end{array}$ \\
\hline PID without VI & 0.0638 & 16.21 & 0.017555 & 1.0793 & 14.44 & 7.267 & 3.432 & 8.173 \\
\hline $\begin{array}{l}\text { PID with } \\
\text { VI-PID }\end{array}$ & 0.0624 & 6.559 & 0.018286 & 1.0806 & 11.74 & 6.117 & 2.984 & 6.438 \\
\hline $\begin{array}{l}\text { PID with } \\
\text { VI-F-PID }\end{array}$ & 0.0611 & 5.125 & 0.002155 & 1.0752 & 5.703 & 3.121 & 2.036 & 4.682 \\
\hline $\begin{array}{c}\text { PID with } \\
\text { VI-FO-F-PID }\end{array}$ & 0.0589 & 4.787 & 0.001732 & 1.0611 & 4.423 & 2.312 & 1.281 & 3.125 \\
\hline
\end{tabular}

Therefore, the HPSREG system with the control approach based on FO based fuzzy PID control technique is quicker, has lower value for steady-state error and offers better damping than that offered by the virtual inertia controller-based FO-PID and PID controller in suppressing deviation in frequency response.

\subsection{Case Study-B: Random Load Perturbation}

The main target of this scenario is to evaluate the performance of the studied HPSREG system with the proposed virtual inertia control-based on FO based fuzzy PID controller under the effect of the uncertainties in load demand trough a random load demand as shown in Figure 5b. Therefore, the studied HPSREG system is examined by implementing a random load demand. Figure 7 displays the frequency and power deviation of the studied HPSREG with the different control strategies; as named for simulation purpose "PID-WithVI-FO-F-PID", "PID-With-VI-FO-PID", "PID-with-VI-PID" and "PID-without-VI" under the impact of the random load as shown in Figure 7.

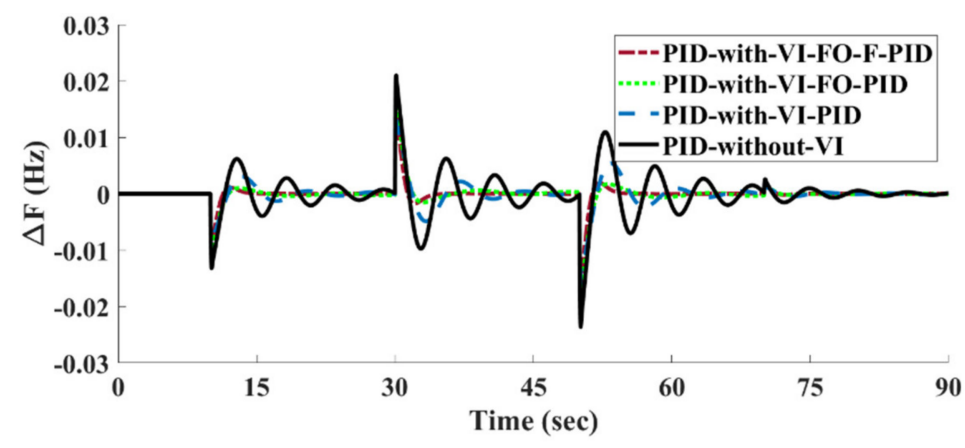

(a)

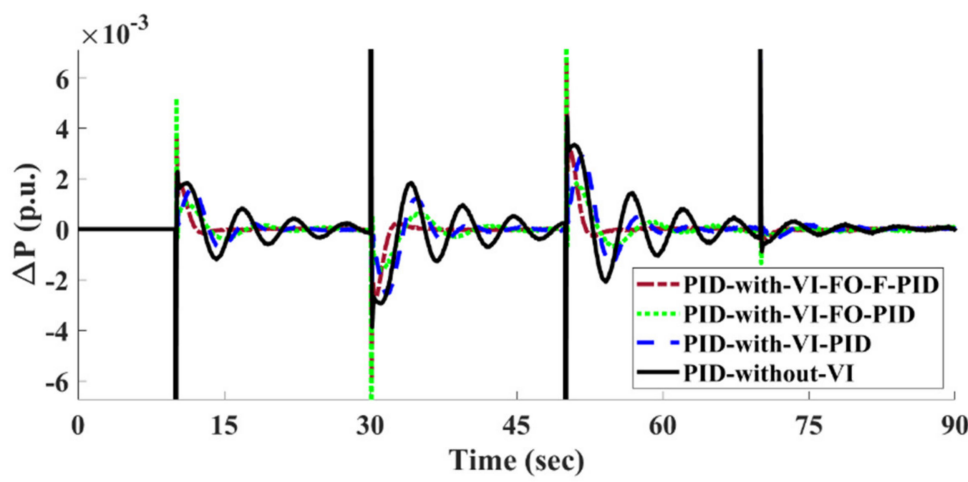

(b)

Figure 7. Dynamic response of HPSREG for random load perturbation (a) $\Delta F(H z)$ and (b) $\Delta P(p . u$.). 
From Figure 7, it is clear that the proposed "PID-With-VI-FO-F-PID" configuration of the studied HPSREG system gives superior performance and more reduction of the frequency and power excursions compared to other control strategies. Where the frequency deviation of the studied HPSREG system with configuration "PID-without-VI" has been maintained within $\pm 0.023 \mathrm{~Hz}$, in the cases of random load. While the configuration "PIDwith-VI-PID" of studied HPSREG system gives a frequency change of $\pm 0.018 \mathrm{~Hz}$ during random load connecting. On the other hand, the frequency deviation of the HPSREG system with "PID-With-VI-FO-PID", configuration has been maintained within a \pm 0.014 $\mathrm{Hz}$ in that cases, while the studied HPSREG system with the "PID-With-VI-FO-F-PID" configuration can maintain the frequency deviation within a $\pm 0.009 \mathrm{~Hz}$.

Thus, the frequency response of the "PID-With-VI-FO-F-PID" configuration with the proposed control strategy based on FO based fuzzy PID controller technique is faster, has a lower steady-state error, and better damped than that by using the FO based PID and PID controller for virtual inertia control.

\subsection{Case Study-C: Load Based Sensitivity Analysis}

In this scenario, a sensitivity analysis of the virtual inertia control-based on FO based fuzzy PID controller of the studied HPSREG is being investigated in order test the robustness of the considered controller. Here, only "PID-With-VI-FO-F-PID" configuration have been considered for sensitivity analysis as the same has been identified as the most effective controller in managing the frequency and power deviation of the studied HPSREG.

"PID-With-VI-FO-F-PID" controller gain parameters has been optimized for $10 \%$ step load perturbation at $t=1 \mathrm{~s}$ (see Figure $5 \mathrm{a}$ ) and then the system has been subjected to different loading condition. Figure 8 displays the frequency and power deviation of the studied HPSREG with $50 \%$ and $100 \%$ increase in load demand than that from the optimized loading condition. From the profile of frequency and power deviation, it may be noted that "PID-With-VI-FO-F-PID" configuration of HPSREG presented its robust nature to the variation in load demand.

The virtual inertia control-based on FO based fuzzy PID controller offers better damping characteristics for frequencies and power oscillations under load sensitivity, that may be observed in terms of decreased $\mathrm{T}_{\mathrm{s}}, \mathrm{Mp}$ and $\mathrm{Tp}$. These improvements in dynamic response profiles may be observed while calculating the transient parameters, as presented in Table 4.

Table 4. Comparative study of dynamic responses offered by the HPSREG under varying loading condition.

\begin{tabular}{ccccccccc}
\hline $\begin{array}{c}\text { Loading } \\
\text { Condition }\end{array}$ & $\begin{array}{c}\boldsymbol{T}_{\boldsymbol{r}} \\
\mathbf{( s )}\end{array}$ & $\begin{array}{c}\boldsymbol{T}_{\boldsymbol{s}} \\
(\mathbf{s})\end{array}$ & $\boldsymbol{M}_{\boldsymbol{P}}$ & $\boldsymbol{T}_{\boldsymbol{P}} \mathbf{( s )}$ & $\begin{array}{c}\text { ISE } \\
\left(\times \mathbf{1 0}^{-\mathbf{5}}\right)\end{array}$ & $\begin{array}{c}\text { ITSE } \\
\left(\times \mathbf{1 0}^{-4}\right)\end{array}$ & $\begin{array}{c}\text { IAE } \\
\left(\times \mathbf{1 0}^{-4}\right)\end{array}$ & $\begin{array}{c}\text { ITAE } \\
\left(\times \mathbf{1 0}^{-3}\right)\end{array}$ \\
\hline True $\left(\Delta P_{L}\right)$ & 0.2943 & 23.3019 & 0.0023 & 1.0612 & 1.871 & 2.941 & 0.973 & 2.014 \\
\hline$+50 \%$ of $\left(\Delta P_{L}\right)$ & 0.2784 & 23.0598 & 0.0031 & 1.0609 & 3.334 & 4.691 & 2.481 & 3.974 \\
\hline$+100 \%$ of $\left(\Delta P_{L}\right)$ & 0.1933 & 23.0621 & 0.0039 & 1.0609 & 5.174 & 6.213 & 3.521 & 5.889 \\
\hline
\end{tabular}

\subsection{Case Study-D: Parameter Based Sensitivity Analysis}

In this scenario also, the sensitivity of only HPSREG with virtual inertia controlbased on FO based fuzzy PID controller (i.e., "PID-With-VI-FO-F-PID" configuration of HPSREG) have been carried out, as this configuration has been reported better than the other considered controllers for the considered HPSREG. Here the parameters of the power system block (i.e., $K_{P}$ and $T_{P}$ ) from HPSREG are Vried and their effect performance has been recorded. The main target of this scenario is to evaluate the performance of the studied HPSREG with virtual inertia control-based on FO based fuzzy PID controller (i.e., "PIDWith-VI-FO-F-PID" configuration of HPSREG) for system parameter variation as stated in Tables 5 and 6 . From Tables 5 and 6 it may be observed that in terms of transient parameters like $T_{S}, M p$ and $T p$, the proposed control for HPSREG offers acceptable response to the variation in parameters. 


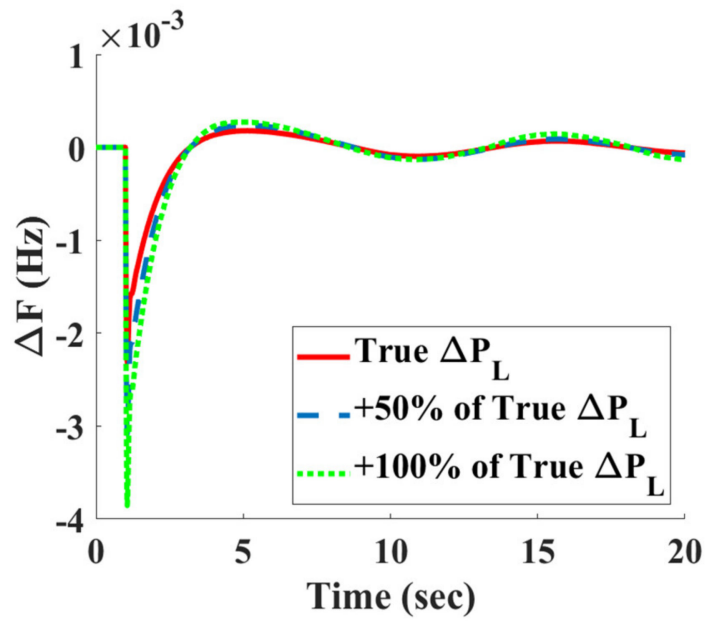

(a)

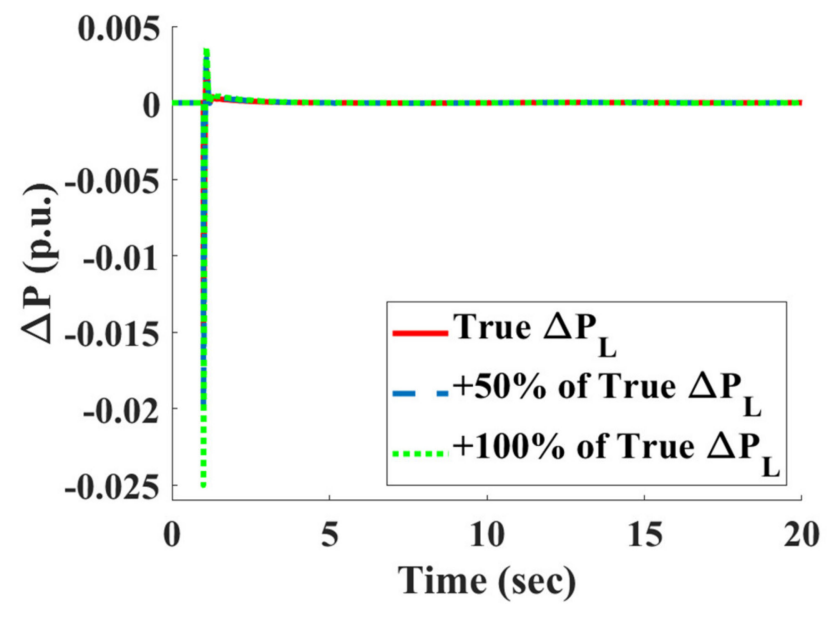

(b)

Figure 8. Sensitivity analysis of the HPSREG with the "PID-With-VI-FO-F-PID" configuration during $+50 \%$ and $+100 \%$ changes in load demand: (a) $\Delta F(H z)$ and (b) $\Delta P(p . u$.).

Table 5. Comparative study of dynamic responses offered by the HPSREG under parameter variation of $K_{P}$.

\begin{tabular}{ccccccccc}
\hline Parameter Variation & $\begin{array}{c}\boldsymbol{T}_{\boldsymbol{r}} \\
\mathbf{( s )}\end{array}$ & $\begin{array}{c}\boldsymbol{T}_{\boldsymbol{s}} \\
\mathbf{( s )}\end{array}$ & $\boldsymbol{M}_{\boldsymbol{P}}$ & $\boldsymbol{T}_{\boldsymbol{P}}(\mathbf{s})$ & $\begin{array}{c}\text { ISE } \\
\left(\times \mathbf{1 0}^{-\mathbf{5}}\right)\end{array}$ & $\begin{array}{c}\text { ITSE } \\
\left(\times \mathbf{1 0}^{-4}\right)\end{array}$ & $\begin{array}{c}\text { IAE } \\
\left(\times \mathbf{1 0}^{-\mathbf{4}}\right)\end{array}$ & $\begin{array}{c}\text { ITAE } \\
\left(\times \mathbf{1 0}^{-\mathbf{3}}\right)\end{array}$ \\
\hline True $K_{P}$ & 0.2209 & 4.2099 & 0.0375 & 1.1965 & 4.423 & 2.312 & 1.281 & 3.125 \\
$-50 \%$ of $K_{P}$ & 0.1475 & 4.5679 & 0.0320 & 1.2881 & 4.715 & 2.764 & 1.774 & 3.659 \\
$+50 \%$ of $K_{P}$ & 0.6127 & 4.1112 & 0.0428 & 1.1147 & 4.271 & 2.177 & 2.463 & 3.078 \\
\hline
\end{tabular}

Table 6. Comparative study of dynamic responses offered by the HPSREG under parameter variation of $T_{P}$.

\begin{tabular}{ccccccccc}
\hline Parameter Variation & $\begin{array}{c}\boldsymbol{T}_{\boldsymbol{r}} \\
\mathbf{( s )}\end{array}$ & $\begin{array}{c}\boldsymbol{T}_{\boldsymbol{s}} \\
(\mathbf{s})\end{array}$ & $\boldsymbol{M}_{\boldsymbol{P}}$ & $\boldsymbol{T}_{\boldsymbol{P}}(\mathbf{s})$ & $\begin{array}{c}\text { ISE } \\
\left(\times \mathbf{1 0}^{-\mathbf{5}}\right)\end{array}$ & $\begin{array}{c}\text { ITSE } \\
\left(\times \mathbf{1 0}^{-\mathbf{4}}\right)\end{array}$ & $\begin{array}{c}\text { IAE } \\
\left(\times \mathbf{1 0}^{-\mathbf{4}}\right)\end{array}$ & $\begin{array}{c}\text { ITAE } \\
\left(\times \mathbf{1 0}^{-\mathbf{3}}\right)\end{array}$ \\
\hline True $T_{P}$ & 0.2209 & 4.2099 & 0.0375 & 1.1965 & 4.423 & 2.012 & 1.281 & 3.125 \\
\hline$-50 \%$ of $T_{P}$ & 0.2239 & 4.2143 & 0.04268 & 1.0869 & 4.253 & 2.356 & 2.249 & 5.546 \\
\hline$+50 \%$ of $T_{P}$ & 0.2249 & 4.2296 & 0.0385 & 1.1969 & 4.864 & 2.666 & 1.814 & 4.619 \\
\hline
\end{tabular}

Figure 9 demonstrates the frequency and power deviation profiles due to the change in the value of $K_{P}$ (gain parameter for the power system block of HPSREG). Moreover, the deviation in frequency and power due to change in $T_{P}$ (time constant parameter for the power system block of HPSREG) has been presented in Figure 10. From Figures 9 and 10 and Tables 5 and 6 , it may be noted that the system performance has not been affected to a remarkable value, therefore Tables 5 and 6 and Figures 9 and 10 vouch for the robustness of the studied HPSREG with the virtual inertia control-based on FO based fuzzy PID controller. 


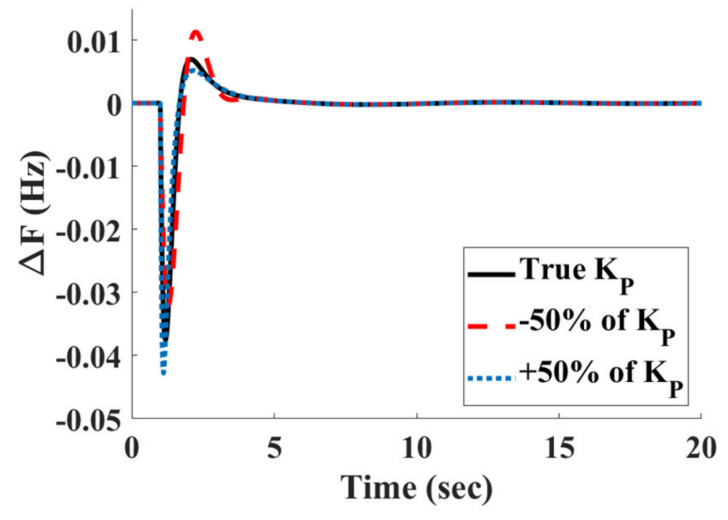

(a)

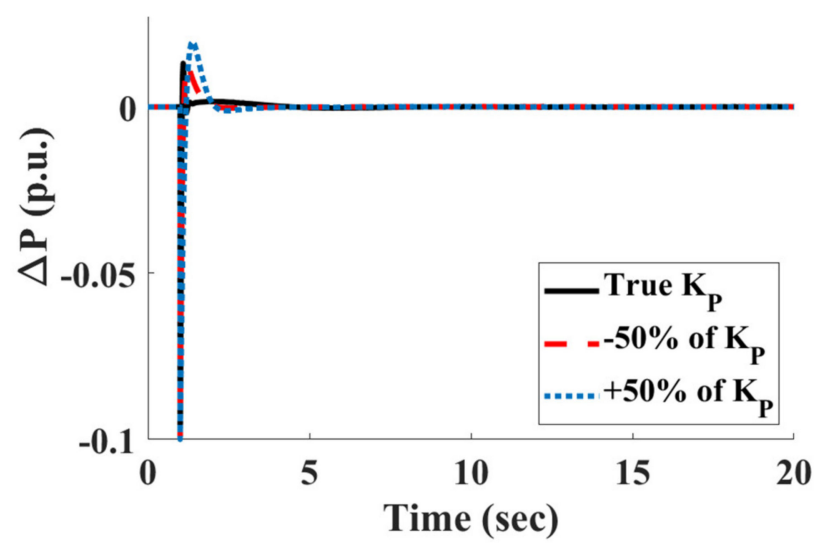

(b)

Figure 9. Sensitivity analysis of the HPSREG with the "PID-With-VI-FO-F-PID" configuration during $\pm 50 \%$ changes in $K_{P}$ : (a) $\Delta F(H z)$ and (b) $\Delta P(p . u$.).

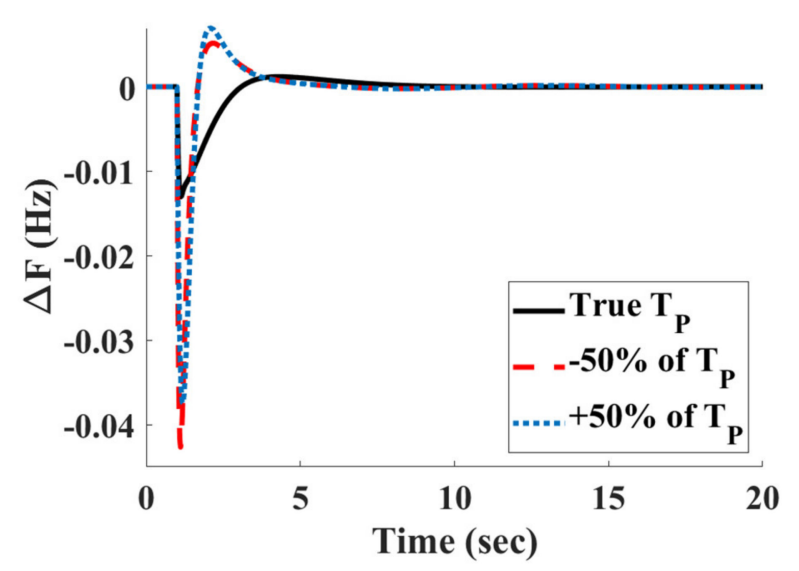

(a)

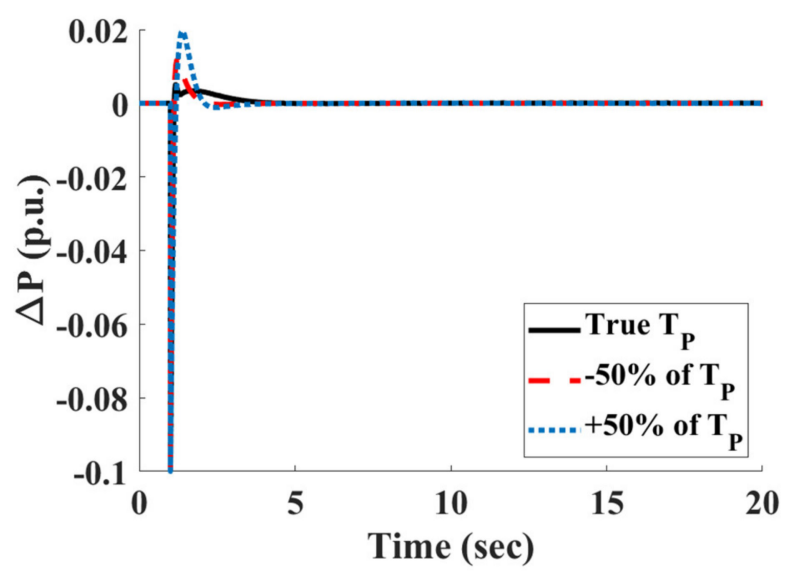

(b)

Figure 10. Sensitivity analysis of the HPSREG with the "PID-With-VI-FO-F-PID" configuration during $\pm 50 \%$ changes in $T_{P}$ : (a) $\Delta F(H z)$ and (b) $\Delta P(p . u$.).

\section{Conclusions and Future Work}

With the increasing penetration of REGs, inverter-interfaced generators are decreasing the overall inertia of the power system. Especially in isolated HPSREGs this manifests itself as system instability and, in the severest situations, cascading outages. The issue will become more significant, considering the surge in amount of REGs connected to power systems/islanded power systems worldwide in future. Therefore, in the undertaken work, FO based fuzzy PID controller method is employed for virtual inertia control to maintain the stability of frequency in an HPSREG system. The considered FO based fuzzy PID controller aims to diminish the impact of load disturbances in the system. The considered HPSREG system comprises of a DEG unit and a WTG unit in association an ESS having the potential of mimicking the effect of inertia in order to control the system small disturbances. All the tunable parameters of the system and controllers (i.e., "PIDWith-VI-FO-F-PID", "PID-With-VI-FO-PID", "PID-with-VI-PID" and "PID-without-VI" based modal configuration) are being tuned using QOHS algorithm. It is first time when the effectiveness of QOHS algorithm has been utilized for virtual inertia control in an isolated system.

The time-domain simulation outcomes uncover that the proposed FO based fuzzy PID controller based virtual inertia control effectively regulates the HPSREG system frequency. 
It shows robust performance in tracking the reference frequency precisely and attenuation of severe load disturbances. When compared with other controllers used in the field, proposed FO based fuzzy PID control technique dramatically improves the HPSREG system frequency and power control performance, enhancing HPSREG system stability and resiliency.

The frequency deviation of the HPSREG system without virtual inertia controller have a settling time of $16.21 \mathrm{~s}$, in the cases of $10 \%$ SLP. While, with the virtual inertia controller based on PID gives settling time of $6.559 \mathrm{~s}$ (i.e., 60\% improvement). On the other hand, the deviation of frequency for the HPSREG system considering virtual inertia controller-based on FO based PID has upheld an improvement over $90 \%$ than that of system with the virtual inertia controller frequency deviation in this case, whereas, with virtual inertia controller-based on FO based fuzzy PID control process may uphold the 33\% enhancement in the settling time of the deviation in frequency than that of virtual inertia controller-based on FO based PID.

The present work has endless scope of future work. The considered model may be extended to integrated standalone models, and may be used as a part of isolated community services provider and many more similar works may be carried out considering the present model. It may also become a part of with-without storage studies and also for the studies related to the sizing of the isolated hybrid systems. Moreover, it may be considered for energy management studies as integrated standalone system also may be undertaken for the protection related studies. Finally, all this simulation work may be developed as a hardware prototype actual real time study.

Author Contributions: Conceptualization, T.M., R.K., H.M., S.M.S.H. and T.S.U.; methodology, T.M. and H.M.; software, T.M. and H.M.; validation, T.M. and H.M.; formal analysis, T.M., R.K., H.M., S.M.S.H. and T.S.U.; investigation, T.M., R.K. and H.M.; data curation, T.M., R.K., H.M.; writing-original draft preparation, T.M., R.K., H.M.; writing-review and editing, S.M.S.H. and T.S.U.; visualization, T.M. and R.K.; project administration, S.M.S.H. and T.S.U.; funding acquisition, S.M.S.H. All authors have read and agreed to the published version of the manuscript.

Funding: This research received no external funding.

Institutional Review Board Statement: Not applicable.

Informed Consent Statement: Not applicable.

Data Availability Statement: Not applicable.

Conflicts of Interest: The authors declare no conflict of interest.

\section{References}

1. Jurasz, J.; Canales, F.; Kies, A.; Guezgouz, M.; Beluco, A. A review on the complementarity of renewable energy sources: Concept, metrics, application and future research directions. Sol. Energy 2020, 195, 703-724. [CrossRef]

2. Hubble, A.H.; Ustun, T.S. Scaling renewable energy based microgrids in underserved communities: Latin America, South Asia, and Sub-Saharan Africa. In Proceedings of the 2016 IEEE PES PowerAfrica, Livingstone, Zambia, 28 June-3 July 2016 ; pp. 134-138.

3. Marzband, M.; Ghazimirsaeid, S.S.; Uppal, H.; Fernando, T. A real-time evaluation of energy management systems for smart hybrid home Microgrids. Electr. Power Syst. Res. 2017, 143, 624-633. [CrossRef]

4. Ustun, T.S.; Aoto, Y. Analysis of Smart Inverter's Impact on the Distribution Network Operation. IEEE Access 2019, 7, 9790-9804. [CrossRef]

5. Bevrani, H.; Watanabe, M.; Mitani, Y. Power System Monitoring and Control; John Wiley \& Sons: Hoboken, NJ, USA, 2014.

6. Rakhshani, E.; Remon, D.; Cantarellas, A.M.; Rodriguez, P. Analysis of derivative control based virtual inertia in mul-ti-area high-voltage direct current interconnected power systems. IET Gener. Transm. Distrib. 2016, 10, 1458-1469. [CrossRef]

7. Bevrani, H.; Ise, T.; Miura, Y. Virtual synchronous generators: A survey and new perspectives. Int. J. Elect. Power Energy Syst. 2014, 54, 244-254. [CrossRef]

8. Lopes, L.A. Self-Tuning Virtual Synchronous Machine: A Control Strategy for Energy Storage Systems to Support Dynamic Frequency Control. IEEE Trans. Energy Convers. 2014, 29, 833-840.

9. Li, D.; Zhu, Q.; Lin, S.; Bian, X.Y. A Self-Adaptive Inertia and Damping Combination Control of VSG to Support Frequency Stability. IEEE Trans. Energy Convers. 2017, 32, 397-398. [CrossRef] 
10. Zhao, H.; Yang, Q.; Zeng, H. Multi-loop virtual synchronous generator control of inverter-based DGs under microgrid dynamics. IET Gener. Transm. Distrib. 2017, 11, 795-803. [CrossRef]

11. Frack, P.F.; Mercado, P.E.; Molina, M.G. Extending the VISMA concept to improve the frequency stability in microgrids. In Proceedings of the 2015 18th International Conference on Intelligent System Application to Power Systems (ISAP), Porto, Portugal, 11-16 September 2015; pp. 1-6.

12. Ustun, T.S. Design and Development of a Communication-Assisted Microgrid Protection System. Ph.D. Thesis, Victoria University, Melbourne, Australia, 2013.

13. Gonzalez-Longatt, F.; Chikuni, E.; Rashayi, E. Effects of the synthesis inertia from wind power on the total system inertia after a frequency disturbance. In Proceedings of the 2013 IEEE International Conference on Industrial Technology (ICIT), Cape Town, South Africa, 5-28 February 2013; pp. 826-832.

14. Mentesidi, K.; Garde, R.; Aguado, M.; Rikos, E. Implementation of a fuzzy logic controller for virtual inertial emulation. In Proceedings of the 2015 International Symposium on Smart Electric Distribution Systems and Technologies (EDST), Vienna, Austria, 8-11 September 2015; pp. 606-611.

15. Hu, Y.; Wei, W.; Peng, Y.; Lei, J. Fuzzy virtual inertia control for virtual synchronous generator. In Proceedings of the 2016 35th Chinese Control Conference (CCC), Chengdu, China, 27-29 July 2016.

16. Kerdphol, T.; Rahman, F.S.; Mitani, Y.; Hongesombut, K.; Küfeoğlu, S. Virtual inertia control-based model predictive control for microgrid frequency stabilization considering high renewable energy integration. Sustainability 2017, 9, 773. [CrossRef]

17. Gheisarnejad, M. An effective hybrid harmony search and cuckoo optimization algorithm based fuzzy PID controller for load frequency control. Appl. Soft Comput. 2018, 65, 121-138. [CrossRef]

18. Mahmoudi, S.M.; Maleki, A.; Ochbelagh, D.R. Optimization of a hybrid energy system with/without considering back-up system by a new technique based on fuzzy logic controller. Energy Convers. Manag. 2021, 229, 113723. [CrossRef]

19. Das, S. Functional Fractional Calculus; Springer International Publishing: Berlin/Heidelberg, Germany, 2011.

20. Das, S.; Pan, I.; Das, S.; Gupta, A. A novel fractional order fuzzy PID controller and its optimal time domain tuning based on integral performance indices. Eng. Appl. Artif. Intell. 2012, 25, 430-442. [CrossRef]

21. Mahto, T.; Mukherjee, V. Fractional order fuzzy PID controller for wind energy-based hybrid power system using quasioppositional harmony search algorithm. IET Gener. Transm. Distrib. 2017, 11, 3299-3309. [CrossRef]

22. Peraza, C.; Valdez, F.; Castro, J.R.; Castillo, O. Fuzzy Dynamic Parameter Adaptation in the Harmony Search Algorithm for the Optimization of the Ball and Beam Controller. Adv. Oper. Res. 2018, 2018, 3092872. [CrossRef]

23. Castillo, O.; Valdez, F.; Soria, J.; Amador-Angulo, L.; Ochoa, P.; Peraza, C. Comparative study in fuzzy controller optimiza-tion using bee colony, differential evolution, and harmony search algorithms. Algorithms 2019, 12, 9. [CrossRef]

24. Valdez, F.; Peraza, C. Dynamic parameter adaptation in the harmony search algorithm for the optimization of interval type-2 fuzzy logic controllers. Soft Comput. 2019, 24, 179-192. [CrossRef]

25. Valdez, F.; Castillo, O.; Peraza, C. Fuzzy Logic in Dynamic Parameter Adaptation of Harmony Search Optimization for Benchmark Functions and Fuzzy Controllers. Int. J. Fuzzy Syst. 2020, 22, 1198-1211. [CrossRef]

26. Mahto, T.; Malik, H.; Mukherjee, V.; Alotaibi, M.A.; Almutairi, A. Renewable generation based hybrid power system control using fractional order-fuzzy controller. Energy Rep. 2021, 7, 641-653. [CrossRef]

27. Gu, D.W.; Petkov, P.; Konstantinov, M.M. Robust Control Design with MATLAB; Springer: New York, NY, USA, 2005.

28. Bhatti, T.S.; Al-Ademi, A.A.; Bansal, N.K. Load frequency control of isolated wind diesel hybrid power systems. Energy Convers. Manag. 1997, 38, 829-837. [CrossRef]

29. Licari, J.; Ekanayake, J.; Moore, I. Inertia response from full-power converter-based permanent magnet wind generators. J. Mod. Power Syst. Clean Energy 2013, 1, 26-33. [CrossRef]

30. Senjyu, T.; Nakaji, T.; Uezato, K.; Funabashi, T. A Hybrid Power System Using Alternative Energy Facilities in Isolated Island. IEEE Trans. Energy Convers. 2005, 20, 406-414. [CrossRef]

31. Kunder, P. Power System Stability and Control; McGraw Hill: New York, NY, USA, 1994.

32. Chen, Y.; Petras, I.; Xue, D. Fractional Order Control—A tutorial; Institute of Electrical and Electronics Engineers (IEEE): Piscataway, NI, USA, 2009; pp. 1397-1411.

33. Oldham, B.; Spanier, J. The Fractional Calculus; Academic Press: New York, NY, USA, 1974.

34. Monje, C.A.; Chen, Y.; Vinagre, B.M.; Xue, D.; Feliu-Batlle, V. Fractional-Order Systems and Controls: Fundamentals and Applications; Springer: London, UK, 2010.

35. Monje, C.A.; Vinagre, B.M.; Feliu, V.; Chen, Y. Tuning and auto-tuning of fractional order controllers for industry applications. Control. Eng. Pract. 2008, 16, 798-812. [CrossRef]

36. Zhong, J. PID Controller Tuning: A Short Tutorial; Purdue University: West Lafayette, IN, USA, 2006.

37. Podlubny, I. Fractional-order systems and PI/sup/spl lambda//D/sup/spl mu//-controllers. IEEE Trans. Autom. Control 1999, 44, 208-214. [CrossRef]

38. Maiti, D.; Biswas, S.; Konar, A. Design of a fractional order PID controller using particle swarm optimization technique. arXiv 2008, arXiv:0810.3776.

39. Mudi, R.; Pal, N. A robust self-tuning scheme for PI- and PD-type fuzzy controllers. IEEE Trans. Fuzzy Syst. 1999, 7, 2-16. [CrossRef] 
40. Lee, C.C. Fuzzy logic in control systems: Fuzzy logic controller-parts 1 and 2. IEEE Trans. Syst. Man Cybern. 1990, $20,404-435$. [CrossRef]

41. Mamdani, E.; Assilian, S. An experiment in linguistic synthesis with a fuzzy logic controller. Int. J. Man Mach. Stud. 1975, 7, 1-13. [CrossRef]

42. Woo, Z.-W.; Chung, H.-Y.; Lin, J.-J. A PID type fuzzy controller with self-tuning scaling factors. Fuzzy Sets Syst. 2000, 115, 321-326. [CrossRef]

43. Banerjee, A.; Mukherjee, V.; Ghoshal, S. Modeling and seeker optimization based simulation for intelligent reactive power control of an isolated hybrid power system. Swarm Evol. Comput. 2013, 13, 85-100. [CrossRef]

44. Geem, Z.W.; Kim, J.H.; Loganathan, G. A New Heuristic Optimization Algorithm: Harmony Search. Simulation 2001, 76, 60-68. [CrossRef]

45. Yang, X.S. Music Inspired Harmony Search Algorithm: Theory and Applications; Springer: Berlin/Heidelberg, Germany, 2009.

46. Banerjee, A.; Mukherjee, V.; Ghoshal, S. An opposition-based harmony search algorithm for engineering optimization problems. Ain Shams Eng. J. 2014, 5, 85-101. [CrossRef]

47. Tizhoosh, H. Opposition-Based Learning: A New Scheme for Machine Intelligence. In Proceedings of the International Conference on Computational Intelligence for Modelling, Control and Automation and International Conference on Intelligent Agents, Web Technologies and Internet Commerce (CIMCA-IAWTIC'06), Vienna, Austria, 28-30 November 2005; pp. 695-701.

48. Rahnamayan, S.; Tizhoosh, H.R.; Salama, M.M. Opposition versus randomness in soft computing techniques. Appl. Soft Comput. 2008, 8, 906-918. [CrossRef]

49. Rahnamayan, S.; Tizhoosh, H.R.; Salama, M.M.A. Quasi-oppositional Differential Evolution. In Proceedings of the 2007 IEEE Congress on Evolutionary Computation, Singapore, 25-28 September 2007; pp. 2229-2236.

50. Chatterjee, A.; Ghoshal, S.P.; Mukherjee, V. Solution of combined economic and emission dispatch problems of power systems by an opposition-based harmony search algorithm. Int. J. Elect. Power Energy Syst. 2012, 39, 9-20. [CrossRef]

51. Mahto, T.; Mukherjee, V. Quasi-oppositional harmony search algorithm and fuzzy logic controller for load frequency stabilisation of an isolated hybrid power system. IET Gen. Trans. Distri. 2015, 9, 427-444. [CrossRef] 